\title{
Evaluation and characterisation of metal sorption and retention by drinking water treatment residuals (WTRs) for environmental remediation
}

\author{
K. A. H. Arab ${ }^{1,3}$ D. F. Thompson ${ }^{2} \cdot$ I. W. Oliver $^{1}$ (I)
}

Received: 31 December 2020 / Revised: 21 August 2021 / Accepted: 13 September 2021 / Published online: 25 September 2021

(c) The Author(s) 2021

\begin{abstract}
Drinking water treatment residuals (WTRs) are wastes generated when water is clarified using aluminium or iron salts. They are increasingly being considered as a resource with potential reuse value, particularly in relation to soil or water remediation. Adsorption-desorption capacity of Al-based (Al-WTR) and Fe-based (Fe-WTR) materials was investigated here for Pb and $\mathrm{Zn}$, both separately and in combination, as a preliminary trial to assess their utility for immobilising contaminant metals in environmental settings. Maximum adsorption observed at the highest test solution concentrations imposed $(400 \mathrm{mg} / \mathrm{L})$ was similar for each WTR type and each metal; Al-WTRs sorbed Zn at $3579 \mathrm{mg} / \mathrm{kg}$ and Pb at $4025 \mathrm{mg} / \mathrm{kg}$, while Fe-WTRs sorbed $\mathrm{Zn}$ and $\mathrm{Pb}$ at $3579 \mathrm{mg} / \mathrm{kg}$ and $3980 \mathrm{mg} / \mathrm{kg}$, respectively. Equilibrium adsorption data were tested against Langmuir, Freundlich, and Temkin isotherm models, which indicated a substantial reserve capacity for further $\mathrm{Pb}$ sorption and that multiple sorption mechanisms were involved. Subsequent desorption tests with $0.001 \mathrm{M} \mathrm{CaCl}_{2}$ solution indicated that $>89.76 \%$ of sorbed metal remained sorbed. When in solution together, both metals were strongly sorbed by WTRs, but a slight preference for $\mathrm{Pb}$ was observed. The results indicate that WTRs would be very effective immobilising agents if placed in contaminated soil or if used to treat contaminated waters.
\end{abstract}

Keywords Water treatment residuals · Adsorption $\cdot$ Isotherms $\cdot$ Remediation $\cdot$ Lead $\cdot$ Zinc

\section{Introduction}

The treatment of raw water for drinking typically involves the addition of aluminium $(\mathrm{Al})$ or iron $(\mathrm{Fe})$ salts as flocculants and coagulants during the water treatment process, which results in the generation of a sludge-like by-product containing the flocculants and the removed impurities that are often referred to as water treatment residuals (WTRs) (Howe et al. 2012).

Editorial responsibility: Samareh Mirkia.

I. W. Oliver

i.oliver@keele.ac.uk

1 School of Geography, Geology and the Environment, Keele University, Keele ST5 5BG, UK

2 School of Chemical and Physical Sciences, Keele University, Keele ST5 5BG2, UK

3 Department of Ecology, College of Science, University of Kufa, Najaf, Iraq
Vast quantities of WTRs (i.e. in the millions to tens of millions of tons) are generated annually across the globe (Basibuyuk and Kalat 2004), with varying proportions of those produced from application of aluminium-based salts (generating what can be referred to as Al-WTR) and those from ferric-based salts (Fe-WTR). One estimate, for the USA alone, was that more than 2 million tons of WTRs are generated every day (Prakash and SenGupta 2003). WTRs may be disposed of in various ways, including burial in general landfill in jurisdictions such as the European Union within which they are classified as inert waste under EU Council Directive 99/31/EC (1999; as cited in Keeley et al. 2014). Substantial amounts of WTRs are indeed sent to landfills for disposal in many countries, and the economic expense of this disposal route is continually rising. However, in addition to the growing expense, landfill disposal of WTRs is increasingly recognised as wasting a potentially useful resource, with reuse options including in water and 
wastewater treatment, soil improvement and construction (Babatunde and Zhao 2007; Ippolito et al. 2011; Turner et al. 2019). Beneficial use of WTRs is therefore increasingly favoured, offering financial advantages and helping to develop a more circular economy with greater levels of materials recycling. However, to determine the ultimate utility of WTRs for removing contaminants from wastewater and/or for immobilising contaminants in soil and sediment pore water, the sorption and retention capacity of WTRs for contaminants must first be established and understood. Such knowledge is also important in terms of placing the use of these and other recovered wastes for pollution management in the wider context of pollution control options now available, including those offered by recently chemically engineered sorbent materials (Liu 2021).

The aims of the study, therefore, were to investigate adsorption and retention by two types of WTRs (one generated at a plant using Al salts, Al-WTRs, and the other generated from the use of Fe salts, Fe-WTRs) of two important potentially toxic elements, $\mathrm{Pb}$ and $\mathrm{Zn}$, that are highly prevalent contaminants in waters and wastes and are on the priority substances (in the case of $\mathrm{Pb}$ ) and specific pollutants (in the case of $\mathrm{Zn}$ ) lists under the Water Framework Directive of the European Union and on the Priority Pollutant List under the Clean Water Act of the USA.

Adsorption and retention of $\mathrm{Pb}$ and $\mathrm{Zn}$ were tested both singularly and in combination, the latter in order to assess the effects of cation adsorption competition. Adsorption isotherms (Henry's, Langmuir, Freundlich and Temkin) were fitted to the data in order to describe, model and examine the adsorption processes.

\section{Materials and methods}

\section{Water treatment residuals source and preparation}

Water treatment residuals (WTRs) from two water treatment plants in Staffordshire, England, were provided by Severn Trent Water. One plant primarily uses Al salts and the other Fe-based salts, generating what is designated here as Al-WTRs and Fe-WTRs, respectively. According to the results from a previous project carried out on the same materials (Howells et al. 2018), the properties of Al-WTRs once dried were $\mathrm{pH}$ $7.34 \pm 0.06, \mathrm{Al}$ content $11.64 \pm 1.08 \% \mathrm{w} / \mathrm{w}$, organic matter (OM) content $28.0 \pm 0.1 \% \mathrm{w} / \mathrm{w}$ and $\mathrm{Fe}$ content $0.91 \pm 0.08 \%$ w/w, while those of Fe-WTRs were $\mathrm{pH} 7.37 \pm 0.01, \mathrm{Fe}$ $17.69 \pm 0.19 \% \mathrm{w} / \mathrm{w}, \mathrm{OM} 25.9 \pm 0.2 \% \mathrm{w} / \mathrm{w}$ and $\mathrm{Al} 0.71 \pm 0.12 \%$ w/w. For this study, the as-received (i.e. moist) WTRs were dried at $30{ }^{\circ} \mathrm{C}$ until they became a stable mass and were ground to pass a 2-mm sieve.

\section{Water treatment residuals (WTRs) adsorption capacity for lead and zinc}

Following commonly employed batch exchange procedures for determining the adsorption capacity of a substance, $2.0 \mathrm{~g}$ WTR samples were equilibrated with $20 \mathrm{~mL}$ solutions with $\mathrm{Pb}$ or $\mathrm{Zn}$ concentrations of 10, 50, 100, 200, 300 or $400 \mathrm{mg} / \mathrm{L}$ (3 replicates for each WTR type at each concentration). Samples were equilibrated via end-over-end shaking $\left(40 \mathrm{rpm} ; \sim 20^{\circ} \mathrm{C}\right)$ for $24 \mathrm{~h}$, which is generally recognised as sufficient time to establish equilibrium (e.g. Coles and Yong 2006). Equilibration was immediately followed by centrifugation, filtration of supernatant using $0.45-\mu \mathrm{m}$ syringe filters, acidification with a drop of trace analysis grade concentrated nitric acid (Primar Plus) and then analysis for metals using ICP-OES (Varian vista) (e.g. as per Dada et al. 2012). Concentrations determined in the equilibrium solutions were used to calculate amounts of metal sorbed to WTRs, and the data were further examined through constructing Henry's, Langmuir, Freundlich and Temkin adsorption isotherms models, as outlined in Table 1. Equation 1, which was reported by Vanderborght and Van Grieken (1977), is used to calculate the quantity of sorbate retained by a unit of mass of the sorbent $\mathrm{Q}_{\mathrm{e}}^{\mathrm{ads}}(\mathrm{mg} / \mathrm{g})$.

$Q_{e}=\left[\left(C_{0}-C_{e}^{a d s}\right) * V\right] / m$

where $\mathrm{C}_{0}=$ initial solution concentration before adsorption; $\mathrm{C}_{\mathrm{e}}$ ads $=$ concentration at adsorption equilibrium; $\mathrm{V}=$ volume of the adsorbate, and $\mathrm{m}=$ mass of WTRs in grams.

The adsorbed amount of $\mathrm{Zn}$ or Pb by each of Al-WTR and Fe-WTR can be expressed as an adsorption percentage (Eq. 2), which is based on the ratio of the mass of adsorbed ions at equilibrium to the initial mass of adsorbate ions in solution (OECD 2000).
Table 1 Linear and nonlinear isotherm equations (Yildrim 2006; Dada et al. 2012)

\begin{tabular}{lll}
\hline Model & Nonlinear equation & Linear form equation \\
\hline Freundlich & $\mathrm{Qe}=\mathrm{Kf}^{*}(\mathrm{Ce})^{\wedge}(1 / \mathrm{n})$ & $\mathrm{Qe}=\mathrm{Kf}^{*}(\mathrm{Ce})^{\wedge}(1 / \mathrm{n})$ \\
Henry's & - & $\mathrm{Qe}=\mathrm{K}_{\mathrm{H}}^{*} \mathrm{Ce}$ \\
Langmuir & $\mathrm{Qe}=\left(\mathrm{b}^{*} \mathrm{Qm} \mathrm{m}^{*} \mathrm{Ce}\right) /\left(1+\mathrm{b}^{*} \mathrm{Ce}\right)$ & $1 / \mathrm{Qe}=(1 / \mathrm{Qm})+[(1 /$ \\
& & $\left.(\mathrm{Qm} * \mathrm{~b}))^{*}(1 / \mathrm{Ce})\right]$ \\
Temkin & $\mathrm{Qe}=\mathrm{B}^{*} \ln \left(\mathrm{AT}^{*} \mathrm{Ce}\right)$ & $\mathrm{Qe}=\mathrm{B} * \ln (\mathrm{AT})+\mathrm{B} * \ln (\mathrm{Ce})$ \\
\hline
\end{tabular}


Adsorption $\%=\frac{\left(\mathrm{C}_{0-} \mathrm{C}_{e}^{a d s}\right) * \mathrm{~V}}{\left(C_{0} * \mathrm{~V}\right)} \times 100 \%$

At its simplest, adsorption of a metal (or other substance) from solution into solid can be expressed as Henry's adsorption isotherm, with $\mathrm{K}_{\mathrm{H}}$ typically denoted as Henry's adsorption constant (units of $\mathrm{L} / \mathrm{g}$ ). However, adsorption onto a solid across a wide concentration range is not typically constant. In order to understand some of the adsorption characteristics of $\mathrm{Zn}$ and $\mathrm{Pb}$ into WTRs, the experimental data were fitted to Henry's, Langmuir, Freundlich and Temkin linearised equations, all of which have been described in detail elsewhere (Dada et al. 2012; Sparks 2003; Yildirim 2006). From a fitted Langmuir isotherm, one can calculate the $\mathrm{Q}_{\mathrm{m}}$ value, which refers to the maximum monolayer coverage capacity $(\mathrm{mg} / \mathrm{g}$ ) onto the adsorbent, assuming that the binding energy of the sites is homogenous and can also determine the ' $b$ ' value which is the term used for the Langmuir isotherm constant (L/mg) (Dada et al. 2012; Bonilla-Petriciolet et al. 2017).

According to the Temkin isotherm, the heat of the adsorption for all adsorbates decreases linearly as the amount of the adsorbed materials on the sorbent increases. An important calculated parameter for this isotherm is often designated the 'B' value, which is the constant related to heat of sorption $(\mathrm{J} /$ $\mathrm{mol}$ ); the AT value is the Temkin isotherm equilibrium constant (L/g) (Dada et al. 2012; Bonilla-Petriciolet et al. 2017). For adsorptions onto adsorbents for which the distribution of heat of adsorption of binding sites is not or cannot be assumed to be uniform, the Freundlich isotherm model is often used. It is a widely applied isotherm for describing adsorption characteristics and generates the following parameters and constants: $1 / \mathrm{n}$, which is dimensionless and is a function of the strength of the adsorption; and $\mathrm{K}_{\mathrm{f}}$ is the Freundlich isotherm constant (with units of $\mathrm{mg}^{1-(1 / \mathrm{n})} \cdot \mathrm{g}^{-1} \cdot \mathrm{L}^{(1 / \mathrm{n})}$ ) (Dada et al. 2012; BonillaPetriciolet et al. 2017). Although widely used for the purpose, determining characteristics of adsorption processes based on the comparison of Freundlich $\mathrm{K}_{\mathrm{f}}$ values can be problematic when $1 / n$ values are not the same or $\mathrm{C}_{\mathrm{e}}$ ads $\neq 1$ because the units of $\mathrm{K}_{\mathrm{f}}$ will be different (Chen et al. 1999). To address this, Chen et al. (1999) proposed a unified adsorption variable $\left(\mathrm{K}_{\mathrm{u}}^{\text {ads }}\right)$ to unify the unit of $\mathrm{K}_{\mathrm{f}}^{\text {ads }}$ to be $\mathrm{L} / \mathrm{g}$. The $\mathrm{K}_{\mathrm{u}}^{\text {ads }}$ is the slope of the isotherm at any value of $\mathrm{C}_{\mathrm{e}}$ ads or $\mathrm{Q}_{\mathrm{e}}$ ads and can be calculated over a range of $\mathrm{C}_{\mathrm{e}}$ ads or $\mathrm{Q}_{\mathrm{e}}^{\text {ads }}$ using $\mathrm{K}_{\mathrm{f}}^{\text {ads }}$ and $1 / \mathrm{n}$ (using Eq. 3 or Eq. 4). Therefore, $K_{u}$ ads is also calculated in the present study:

$\mathrm{K}_{u}^{a d s}=\mathrm{K}_{f}^{a d s} / C_{\mathrm{e}}^{a d s(n-1) / n}$

$\mathrm{K}_{u}^{a d s}=\mathrm{K}_{f}^{a d s n} / Q e^{a d s n-1}$
Thermodynamic data such as the standard adsorption energy can be obtained from Langmuir and Temkin equation using Eq. 5 (Kim et al. 2004):

$\mathrm{K}=e^{-\Delta G_{a d s}^{0} / R T}$

\section{Desorption of $\mathrm{Pb}$ and $\mathrm{Zn}$}

The desorbability of $\mathrm{Zn}$ and $\mathrm{Pb}$ bound to Al-WTRs and Fe-WTRs was determined in batch desorption experiments to determine the degree of reversibility of adsorption by the materials, that is, to determine how well they retain the pollutant metals after exposure to clean solution. Desorption experiments were conducted on the $2 \mathrm{~g}$ samples after removal of the supernatant following the initial equilibration process described above for the adsorption experiment. In order to facilitate accurate desorption measurements, and specifically to allow any metals remaining entrained in the WTRs after solution removal to be fully accounted and adjusted for in the calculations, the mass of each tube had been recorded before adding $\mathrm{Pb}$ or $\mathrm{Zn}$ solution in the sorption experiment and was recorded again at the end of the batch adsorption equilibrium experiments (i.e. after centrifugation and solution removal). The difference in mass enabled calculation of the remaining volume of solution within each tube, and this, together with the measured concentrations of metals in the removed solution, allowed calculation of the amount of entrained metals in that remaining solution.

For desorption, the removed supernatant was replaced by fresh $0.001 \mathrm{M} \mathrm{CaCl}_{2}$ solution and the samples were shaken (40 rpm; $20^{\circ} \mathrm{C}$ ) again for $24 \mathrm{~h}$, which was immediately followed by centrifugation, filtration using $0.45-\mu \mathrm{m}$ syringe filters and then analysis for metals using ICP-OES. Concentrations measured in the $0.001 \mathrm{M} \mathrm{CaCl}_{2}$ desorption supernatant solutions $\left(\mathrm{C}_{\mathrm{e}}{ }^{\text {des }}\right)$, corrected for the calculated amounts of entrained metals remaining from the initial sorption solution, were used to express the desorbed amount of $\mathrm{Zn}$ or $\mathrm{Pb}$ from each of Al-WTRs and Fe-WTRs as a desorption percentage (Eq. 6; OECD 2000).

$$
\text { desorption } \%=\frac{\left(\mathrm{C}_{e}^{\text {des } * \mathrm{~V})}\right.}{\left(\mathrm{C}_{o} * \mathrm{~V}\right)-\left(\mathrm{C}_{e}^{a d s} * V\right)} \times 100 \%
$$

\section{Adsorption of $\mathrm{Zn}-\mathrm{Pb}$ ions in combination}

In addition to separate adsorption experiments with $\mathrm{Zn}$ and $\mathrm{Pb}$ individually, adsorption experiments with both $\mathrm{Zn}$ and $\mathrm{Pb}$ present in solution were conducted to examine competitive 
adsorption. The experiments were carried out as described above, including the desorption assessment, but with modified initial solution concentrations of (1) $10 \mathrm{mg} / \mathrm{L}$ (both $\mathrm{Pb}$ and $\mathrm{Zn}$ ) and (2) $50 \mathrm{mg} / \mathrm{L}$ (both $\mathrm{Pb}$ and $\mathrm{Zn}$ ). Statistical assessments of sorption and desorption were conducted via $t$ tests and Mood's median tests according to data distribution (normality) types using the Real Statistics Resource Pack software (Release 7.6; www.real-statistics.com).

\section{Results and discussion}

\section{Water treatment residuals (WTRs) adsorption capacity for lead and zinc}

Adsorption of both $\mathrm{Pb}$ and $\mathrm{Zn}$ was very high at all concentrations tested and on both types of WTRs, with the maximum amounts adsorbed at the highest solution concentrations imposed ( $400 \mathrm{mg} / \mathrm{L}$ ) equating to $4025 \mathrm{mg} / \mathrm{kg}$ for $\mathrm{Pb}$ and $3579 \mathrm{mg} / \mathrm{kg}$ for $\mathrm{Zn}$ on Al-WTRs (Table 2 and Fig. 1). For Fe-WTRs, it was $3980 \mathrm{mg} / \mathrm{kg}$ for $\mathrm{Pb}$ and $3579 \mathrm{mg} / \mathrm{kg}$ for $\mathrm{Zn}$ (Table 2 and Fig. 1). Indeed, in all tested concentrations adsorption was $>92 \%$ (thus explaining the very similar maximum adsorption values recorded). Moreover, the realised $\mathrm{Zn}$ and $\mathrm{Pb}$ adsorption capacities of the Al-WTR and Fe-WTR increased linearly with increasing initial concentration of adsorbate $\left(\mathrm{C}_{0}\right)$, as shown in Fig. 1, indicating that adsorption maxima had not been reached for either WTR type (Table 2 and Fig. 1).

Adsorption isotherms of $\mathrm{Zn}$ and $\mathrm{Pb}$ ions in a mono-metal system on Fe-WTR and Al-WTR were created (Fig. 2). The shapes of the isotherms for adsorption of $\mathrm{Zn}$ onto both WTRs can be described as being similar to the 'type I' or 'L curve' isotherm (i.e. asymptotic towards a possible maximum, suggesting that adsorption may be limited to a single monolayer on the surface) (Sparks 2003; Lowell et al. 2012), while $\mathrm{Pb}$ adsorption onto Al-WTRs showed a ' $\mathrm{H}$ ' shape or

Table 2 Adsorbed amount, $\mathrm{Q}_{\mathrm{e}}(\mathrm{mg} / \mathrm{kg})$, and adsorption percentage of total metal in solution, for $\mathrm{Zn}$ and $\mathrm{Pb}$ ions in mono-metal systems with Fe-WTR and Al-WTR as sorbent when $2.0 \mathrm{~g}$ solids were exposed to $20 \mathrm{~mL}$ solutions at concentrations across the range 10 to $400 \mathrm{mg} / \mathrm{L}$ metal

\begin{tabular}{lll}
\hline Test & Range $\mathrm{Q}_{\mathrm{e}}(\mathrm{mg} / \mathrm{kg})$ & $\begin{array}{l}\text { Range of } \\
\text { adsorption } \\
\%\end{array}$ \\
\hline $\mathrm{Zn}$ on Al-WTR & $86.92-3579.28$ & $97-93$ \\
$\mathrm{Zn}$ on Fe-WTR & $86.92-3579.77$ & $97-92$ \\
$\mathrm{~Pb}$ on Al-WTR & $104.90-4025.50$ & $97-100$ \\
$\mathrm{~Pb}$ on Fe-WTR & $103.20-3980.20$ & $96-99$ \\
\hline
\end{tabular}

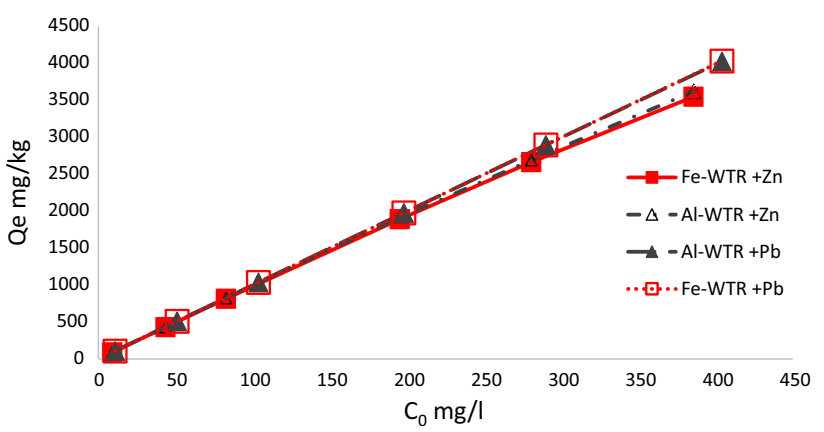

Fig. 1 Effect of initial solution concentration $\left(\mathrm{C}_{0}\right)$ on $\mathrm{Zn}$ and $\mathrm{Pb}$ adsorption (Qe, mg/kg) by Al-WTR and Fe-WTR

'Henry' isotherm that indicates strong adsorbate-adsorbent interactions such as inner-sphere complex formation (Sparks 2003). The shape of the isotherm for $\mathrm{Pb}$ onto Fe-WTRs was intermediate of these, showing aspects of both.

The experimental data reveal that the maximum monolayer coverage capacity $\left(\mathrm{Q}_{\mathrm{m}}\right)$ of the $\mathrm{Zn}$ adsorption onto Fe-WTR and Al-WTR from Langmuir isotherm models was $4.38 \mathrm{mg} / \mathrm{g}$ and $4.68 \mathrm{mg} / \mathrm{g}$, respectively, and that the Langmuir isotherm constants (b) were $0.13 \mathrm{~L} / \mathrm{mg}$ for $\mathrm{Zn}$ adsorption into both WTRs (Table 3). Adjusted R-squared, $\mathrm{R}^{2}(\operatorname{adj})$, values were 0.92 and 0.86 for $\mathrm{Zn}+\mathrm{Fe}-\mathrm{WTR}$ and $\mathrm{Zn}+\mathrm{Al}$-WTRs, respectively, indicating that the adsorption data fitted well to the Langmuir isotherm model. However, the Langmuir isotherm model did not fit $\mathrm{Pb}$ adsorption data for either Fe-WTR or Al-WTR (see Table 3), likely reflecting that sorption maxima were not approached for $\mathrm{Pb}$.

From Freundlich isotherms, the $1 / \mathrm{n}$ values of $\mathrm{Zn}$ adsorption onto Fe-WTR and Al-WTR were 0.68 and 0.74 , respectively (Table 3 ), while $1 / \mathrm{n}$ value for $\mathrm{Pb}$ adsorption onto Fe-WTR was 0.87 . The Freundlich model did not fit the equilibrium adsorption data for Pb onto Al-WTRs. The

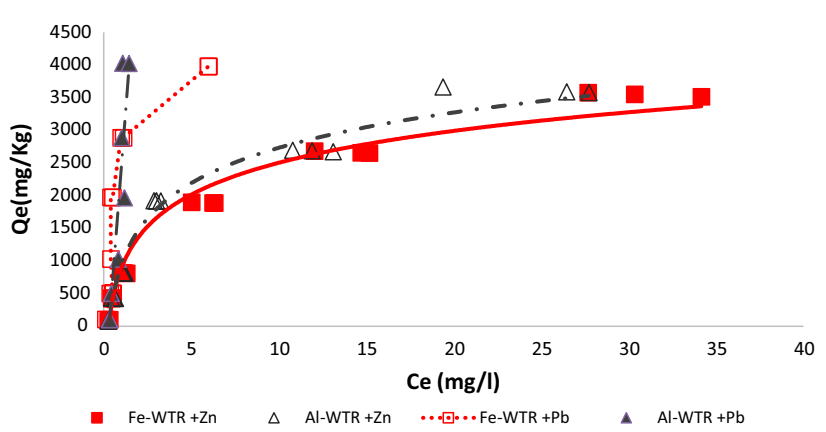

Fig. 2 Adsorption isotherms in a mono-metal system for: Al-WTR with Zn, Al-WTR with Pb, Fe-WTR with Zn and Fe-WTR with Pb. Isotherms constructed using Eq. 1 (see main text). Qe is the mass of sorbate (i.e. $\mathrm{Pb}$ or $\mathrm{Zn}$ ) retained per unit mass of the WTR sorbent; $\mathrm{Ce}$ is the solution concentration of $\mathrm{Pb}$ or $\mathrm{Zn}$ at equilibrium. The ICPOES detection limit for $\mathrm{Zn}$ was $0.27(\mathrm{mg} / \mathrm{l})$ and for $\mathrm{Pb}$ was $0.1(\mathrm{mg} / \mathrm{l})$ 
International Journal of Environmental Science and Technology (2022) 19:7727-7736

7731

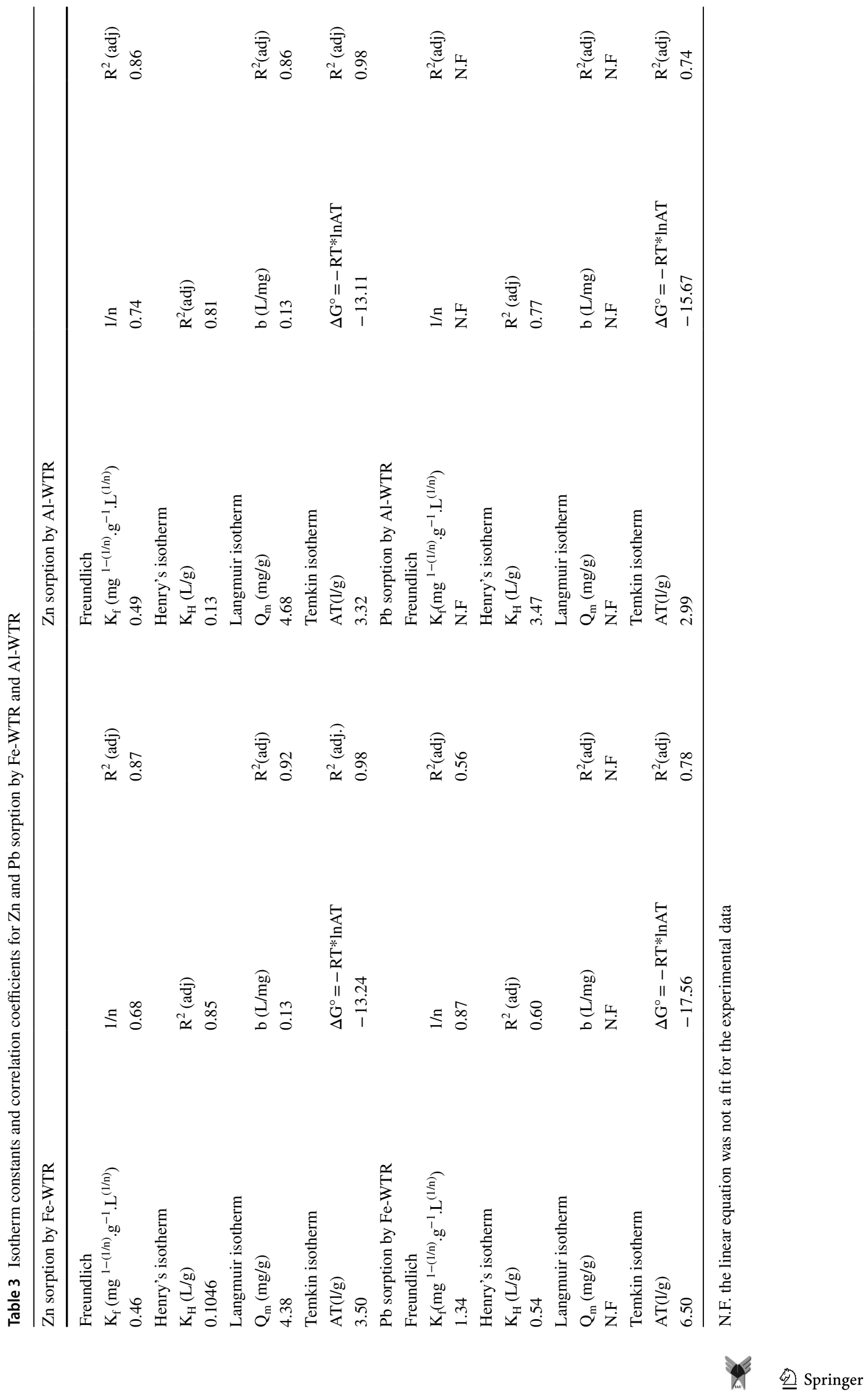


Table $4 \mathrm{~K}_{\mathrm{u}}\left(\mathrm{L} / \mathrm{g}\right.$ ) for Zn sorption by Al-WTR and Fe-WTR and Pb sorption by Fe-WTR*; calculated over a range of $\mathrm{C}_{\mathrm{e}}$ values (see Eq. 3). Values are means \pm standard deviation $(n=3)$

\begin{tabular}{|c|c|c|c|c|c|}
\hline \multicolumn{2}{|c|}{$\mathrm{Fe}-\mathrm{WTR}+\mathrm{Zn}$} & \multicolumn{2}{|c|}{$\mathrm{Al}-\mathrm{WTR}+\mathrm{Zn}$} & \multicolumn{2}{|c|}{$\mathrm{Fe}-\mathrm{WTR}+\mathrm{Pb}$} \\
\hline Ce mg/l & $\mathrm{Ku} \mathrm{L/g}$ & $\mathrm{Ce} \mathrm{mg} / \mathrm{l}$ & $\mathrm{Ku} \mathrm{L/g}$ & $\mathrm{Ce} \mathrm{mg} / \mathrm{l}$ & $\mathrm{Ku} \mathrm{L} / \mathrm{g}$ \\
\hline 0.07 & $0.70 \pm 0.00$ & 0.01 & $0.69 \pm 0.00$ & 0.23 & $1.65 \pm 0.16$ \\
\hline 0.39 & $0.59 \pm 0.01$ & 0.06 & $0.57 \pm 0.03$ & 0.45 & $1.49 \pm 0.05$ \\
\hline 1.18 & $0.44 \pm 0.01$ & 0.31 & $0.47 \pm 0.01$ & 0.45 & $1.49 \pm 0.03$ \\
\hline 5.87 & $0.26 \pm 0.01$ & 3.85 & $0.37 \pm 0.01$ & 0.46 & $1.48 \pm 0.03$ \\
\hline 13.98 & $0.20 \pm 0.01$ & 11.40 & $0.26 \pm 0.01$ & 1.06 & $1.33 \pm 0.01$ \\
\hline 30.73 & $0.15 \pm 0.00$ & 23.54 & $0.21 \pm 0.01$ & 5.99 & $1.06 \pm 0.00$ \\
\hline
\end{tabular}

* Ku values for adsorption of $\mathrm{Pb}$ on Al-WTR could not be calculated because those experimental data did not fit the Freundlich linear equation

Table 5 Sorption percentage (\%) of $\mathrm{Zn}$ and $\mathrm{Pb}$ when in binary solution together and desorption percentage $(\%$ of adsorbed metal released) when samples were re-extracted with $0.001 \mathrm{M} \mathrm{CaCl}_{2}$ (values are means \pm standard deviation, with $\mathrm{n}=3$ )

\begin{tabular}{lcccc}
\hline $\begin{array}{l}\text { Initial solution concen- } \\
\text { tration }(\mathrm{mg} / \mathrm{L})\end{array}$ & $\mathrm{Pb}$ : Al-WTR & $\mathrm{Zn}$ : Al-WTR & Pb: Fe-WTR & Zn: Fe-WTR \\
\hline $\begin{array}{l}\text { Sorption \% } \\
10 \mathrm{~Pb}+10 \mathrm{Zn}\end{array}$ & $100 \pm 0.00^{*}$ & $98.35 \pm 0.22$ & $100 \pm 0.00^{*}$ & $99.89 \pm 0.01$ \\
$50 \mathrm{~Pb}+50 \mathrm{Zn}$ & $100 \pm 0.00^{*}$ & $99.72 \pm 0.04$ & $100 \pm 0.00^{*}$ & $98.87 \pm 0.02$ \\
Desorption \% & & & \\
$10 \mathrm{~Pb}+10 \mathrm{Zn}$ & $0.00 \pm 0.00^{* *}$ & $3.92 \pm 0.01$ & $0.00 \pm 0.00^{* *}$ & $0.44 \pm 0.00$ \\
$50 \mathrm{~Pb}+50 \mathrm{Zn}$ & $0.00 \pm 0.00^{* *}$ & $2.57 \pm 0.00$ & $0.00 \pm 0.00^{* *}$ & $0.03 \pm 0.00$ \\
\hline
\end{tabular}

*The greater sorption of $\mathrm{Pb}$ relative to $\mathrm{Zn}$ is statistically significant $(p<0.05)$ according to $\mathrm{t}$ tests or Moods' median test (as appropriate for data distribution)

**The lower desorption of $\mathrm{Pb}$ relative to $\mathrm{Zn}$ is statistically significant $(p<0.05)$ according to $\mathrm{t}$ tests or Moods' median test (as appropriate for data distribution) values of $R^{2}$ (adj) indicate that the Freundlich isotherm did describe the majority of the data accurately for $\mathrm{Zn}$ adsorption onto both WTRs, having $\mathrm{R}^{2}(\mathrm{adj})$ values of $0.86-0.87$ (Table 3), while for $\mathrm{Pb}$ adsorption onto Fe-WTR it was 0.56 . In order to facilitate better comparison of the Kf values when the $1 / \mathrm{n}$ values are different, $\mathrm{Ku}$ values were calculated over a range of Ce values (Eq. 3) to unify the unit of Kf (Chen et al. 1999). The Ku values (L/g) of $\mathrm{Zn}$ adsorption onto Fe-WTR and Al-WTR (from lowest to highest imposed concentrations) ranged $0.70-0.15$ and $0.69-0.21$, respectively, while $\mathrm{Ku}$ values for $\mathrm{Pb}$ adsorption onto Fe-WTR ranged 1.65-1.06 L/g (Table 4).
From the Temkin model, the equilibrium constant AT values of $\mathrm{Zn}$ adsorption onto Fe-WTR and Al-WTR were $3.50 \mathrm{l} / \mathrm{g}$ and $3.32 \mathrm{l} / \mathrm{g}$, respectively, and the $\mathrm{R}^{2}$ (adj) value was 0.97 for both, while AT values of $\mathrm{Pb}$ adsorption onto $\mathrm{Fe}$ WTR and Al-WTR were $6.50 \mathrm{l} / \mathrm{g}$ and $2.99 \mathrm{l} / \mathrm{g}$, respectively, and the $\mathrm{R}^{2}(\operatorname{adj})$ values were 0.77 and 0.74 , respectively (Table 3). The standard Gibbs free energy of the adsorption can be calculated using Eq. 5. Based on the Temkin constant AT, the standard Gibbs free energy of Zn adsorption onto Fe-WTR and Al-WTR was - 13.24 and - $13.11 \mathrm{~kJ} /$ mol, respectively, and of $\mathrm{Pb}$ adsorption onto Fe-WTR and Al-WTR was -17.56 and $-15.67 \mathrm{~kJ} / \mathrm{mol}$, respectively. These results indicate that $\mathrm{Pb}$ adsorption has more negative
Table 6 Desorption percentages (\% of adsorbed metal released \pm standard deviation) for $\mathrm{Zn}$ and $\mathrm{Pb}$ ions in a monometal system on Fe-WTR and Al-WTR

\begin{tabular}{lllll}
\hline $\begin{array}{l}\text { Initial solution conc. in } \\
\text { adsorption step (mg/L) }\end{array}$ & $\begin{array}{l}\text { Fe-WTR }+\mathrm{Zn} \\
\text { Desorbed mean } \%\end{array}$ & $\begin{array}{l}\text { Al-WTR }+\mathrm{Zn} \\
\text { Desorbed mean } \%\end{array}$ & $\begin{array}{l}\text { Fe-WTR }+\mathrm{Pb} \\
\text { Desorbed mean } \%\end{array}$ & $\begin{array}{l}\text { Al-WTR }+\mathrm{Pb} \\
\text { Desorbed mean \% }\end{array}$ \\
\hline 10 & $2.24 \pm 1.56$ & $7.10 \pm 2.77$ & $0.02 \pm 0.00$ & $6.24 \pm 1.23$ \\
50 & $0.86 \pm 0.19$ & $1.31 \pm 0.56$ & $0.00 \pm 0.00$ & $1.35 \pm 0.01$ \\
100 & $0.45 \pm 0.08$ & $0.77 \pm 0.16$ & $0.00 \pm 0.00$ & $0.82 \pm 0.21$ \\
200 & $0.26 \pm 0.03$ & $1.40 \pm 0.12$ & $0.00 \pm 0.00$ & $0.45 \pm 0.06$ \\
300 & $0.26 \pm 0.03$ & $1.22 \pm 0.01$ & $0.00 \pm 0.00$ & $0.31 \pm 0.03$ \\
400 & $0.36 \pm 0.06$ & $1.26 \pm 0.03$ & $0.00 \pm 0.00$ & $0.23 \pm 0.06$ \\
\hline
\end{tabular}


values and is thus more easily adsorbed on WTRs than Zn, which supports the results described above in that the more $\mathrm{H}$-shaped isotherms for $\mathrm{Pb}$ indicated that saturation was not approached.

\section{Competitive adsorption/desorption of $\mathrm{Zn}-\mathrm{Pb}$ ions}

Removal efficiency from solution was $100 \%$ for $\mathrm{Pb}$ and almost 100\% (> 98\%) for Zn (Table 5), revealing that WTRs had high capacity for sorbing both metals when present together but also demonstrating a marginally higher affinity for Pb sorption by Al-WTR and Fe-WTR compared with Zn ions that was statistically significant. A similar pattern was evident in the desorption findings in which no $\mathrm{Pb}$ was detectably released from either WTR type, while only a very small percentage of adsorbed $\mathrm{Zn}(0.03-3.92 \%)$ was released, thus also indicating a marginally higher affinity and/or binding retention of $\mathrm{Pb}$ of the cationic adsorption sites of the WTRs than that for $\mathrm{Zn}$ ions (Table 5).

\section{Desorption of $\mathrm{Pb}$ and $\mathrm{Zn}$ (single element)}

The desorption percentages (i.e. the percentage of adsorbed metal that was extracted by $0.001 \mathrm{M} \mathrm{CaCl}_{2}$ ) of both $\mathrm{Pb}$ and Zn were very low for all samples for both types of WTRs (Table 6). For example, desorption percentages from WTRs originally exposed to $400 \mathrm{mg} / \mathrm{l}$ metal solutions were $0.23 \pm 0.06 \%$ and $1.26 \pm 0.03 \%$ for $\mathrm{Pb}$ and $\mathrm{Zn}$, respectively, for the Al-WTRs. Samples of Al-WTRs subjected to the lowest initial concentration of $\mathrm{Pb}$ and $\mathrm{Zn}$, i.e. $10 \mathrm{mg} / \mathrm{l}$, had desorption percentage values of $6.24 \pm 1.23 \%$ and $7.10 \pm 2.77 \%$ for $\mathrm{Pb}$ and $\mathrm{Zn}$, respectively (Table 6). For the Fe-WTRs, desorption percentages for samples subjected to initial concentrations of $\mathrm{Pb}$ and $\mathrm{Zn}$ of $400 \mathrm{mg} / \mathrm{l}$ were $0.00 \pm 0.00 \%$ and $0.36 \pm 0.06 \%$, respectively. For Fe-WTR samples subjected to the lowest initial concentration of $\mathrm{Pb}$ and $\mathrm{Zn}$, i.e. $10 \mathrm{mg} / \mathrm{l}$, the desorption percentages were $0.02 \pm 0.00 \%$ and $2.24 \pm 1.56 \%$ for $\mathrm{Pb}$ and $\mathrm{Zn}$, respectively (Table 6). This again shows that both types of WTRs have high capacity for binding and retaining metals. Extraction of WTR constituent metals by the sorption and desorption solutions was also negligible, in keeping with previous experiments in our laboratory on these WTRs that showed Al, Fe and other metals were not appreciatively mobile unless the $\mathrm{pH}$ was forced below 5 (Howells et al. 2018).

\section{Discussion}

\section{Adsorption and desorption}

The levels of sorption demonstrated here $(\sim 4000 \mathrm{mg} / \mathrm{kg}$, without reaching saturation) provide definitive values that add to the growing literature on WTR sorption capacity and strength (e.g. Chiang et al. 2012; Zhou and Haynes 2011; Silvetti et al. 2015). From the Langmuir isotherm, which fit the data well for $\mathrm{Zn}$ sorption (but not for $\mathrm{Pb}$ ), the maximum monolayer coverage capacity $\left(\mathrm{Q}_{\mathrm{m}}\right)$ of the $\mathrm{Zn}$ adsorption onto Fe-WTR and Al-WTR could be calculated as $4.38 \mathrm{mg} / \mathrm{g}$ and $4.68 \mathrm{mg} / \mathrm{g}$, respectively, which is greater than that reported for comparable recovered materials such as activated carbon (1.23 mg/g; Üçer et al. 2006), hazelnut shells $(1.78 \mathrm{mg} / \mathrm{g}$; Cimino et al. 2000) and treated pine bark $(1.18 \mathrm{mg} / \mathrm{g}$; Vazquez et al. 1994) but lower than that reported for coal fly ash (11.11 mg/g; Pehlivan et al. 2006). One could speculate that sorption beyond this theoretical monolayer maximum may be achieved through continued coagulation and flocculation effects on the metal ions in solution by the oxide and hydroxide $\left(\mathrm{OH}^{-}\right)$surfaces of the WTRs through indirect hydrogen bonding forces, which have been shown to be important in comparable situations (Dash et al. 2011). Any hydroxide-bearing colloids released by the WTRs could also have a similar effect. It is interesting that the Al-WTRs and the Fe-WTRs both performed equally at sorbing Zn, whereas the study by Chiang et al. (2012) found that FeWTRs outperformed Al-WTRs in this regard. One could speculate that this inconsistency across studies might reflect wider differences between the plants from where Chiang and partners obtained their WTRs compared to those plants from where WTRs were obtained for the present study, i.e. wider differences in raw water characteristics and/or differences in supporting electrolytes or levels of lime added during water treatment, which could have made a greater difference between their WTRs beyond just that created from the use of different primary coagulants.

The $\mathrm{Zn}$ adsorption isotherms (Fig. 2) clearly indicated a high affinity of both WTR materials for this metal. However, although there was a very high adsorption efficiency across the entire range of concentrations imposed (always $>93 \%$, Table 2), there was a relative decrease in the adsorption efficiency at higher concentrations which, based on the Temkin model, might be attributed to a process in which the heat of adsorption of all the molecules in the layer decreases linearly with an increase in the coverage of WTRs surface due to adsorbent-adsorbate interactions (Bonilla-Petriciolet et al. 2017). Or, as implied by the Type I curves for Zn (Fig. 2), the decreased adsorption efficiency observed could simply be due to a decrease in the remaining available adsorbing sites as the amount of surface-bound $\mathrm{Zn}$ increased. It is also possible that a combination of these factors was at work. The Type I isotherms also indicate a pattern of adsorption that is consistent with that of microporous materials with narrow pores that limit multilayer adsorption (Lowell et al. 2012), which can consequently limit the overall amount adsorbed. The nature of the pores within WTRs was examined in part by Makris et al. (2004) who noticed that the carbon dioxide 
gas adsorption (232 pm width) was greater than that of $\mathrm{N}_{2}$ (370 pm width), suggesting steric restriction of $\mathrm{N}_{2}$ diffusion by narrow micropore openings. If WTRs typically have micropores of this scale, steric restriction might inhibit multilayer adsorption to some degree because of the size of $\mathrm{Zn}$ hydrated ionic radii.

Contrastingly, the more H-type adsorption isotherm curves for $\mathrm{Pb}$, particularly on Al-WTRs, indicated low surface saturation coverages (e.g. $\mathrm{Q}_{\mathrm{e}} / \mathrm{Q}_{\mathrm{m}}<0.1$ ). This suggests that for $\mathrm{Pb}$ the WTRs had a great reserve capacity for further adsorption. It is known that $\mathrm{Pb}$ has more affinity for organic matter than does $\mathrm{Zn}$, based on a typical affinity sequence of organic matter for metals (McBride 1989); thus, it is plausible that the organic matter content of the WTRs $(28 \%$ and $26 \%$ by mass, respectively) played an important role in the higher $\mathrm{Pb}$ sorption capacity observed here. Nevertheless, because the organic matter percentage of the respective WTRs was so similar it is unlikely that variation in the organic matter content can account for the different shaped isotherms with respect to $\mathrm{Pb}$ sorption (i.e. the Al-WTRs had a classic $\mathrm{H}$ shape, whereas the Fe-WTRs had a more intermediate shape). A chemical precipitation/fixation process might thus have been involved for Pb on Al-WTRs. However, as high adsorption was observed with both WTRs used in the present study it is possible that a chemical precipitation might contribute to the high removal of both $\mathrm{Pb}$ and $\mathrm{Zn}$ in the case of both WTR types in addition to the adsorption processes. In relation to that, it is worth noting that based on values of standard electrode potential $\mathrm{E}^{\circ}$ for $\mathrm{Pb}$ and $\mathrm{Al}$ in an electrochemical series, reduction reactions of the $\mathrm{Pb}$ could possibly occur in the presence of Al. Such a process would result in tight binding of $\mathrm{Pb}$ to the surface that would not be easily dislodged (i.e. strong retention).

Using the Temkin isotherm model (which was the best fitting model for adsorption of Zn onto WTRs as well as for $\mathrm{Pb}$ onto Fe-WTRs), the free energy of the sorption process can be calculated. That is, applying the Temkin adsorption constant in the classical Van't Hoff equation can calculate standard Gibbs free energy for the process. Standard Gibbs free energy $\left(\Delta G^{\circ}\right)$ values for adsorption of $\mathrm{Zn}$ onto $\mathrm{Fe}$ WTR and Al-WTR were -13.24 and - 13.11, respectively, while for adsorption of $\mathrm{Pb}$ onto Fe-WTR and Al-WTR were -17.56 and -15.67 , respectively. Being minus (-) in sign, this indicates that the sorption processes would occur spontaneously and further emphasises that the sorption processes were thermodynamically favourable.

In terms of the slight preference for $\mathrm{Pb}$ sorption over $\mathrm{Zn}$ observed, it may be that the ions with the greatest charge density (ratio of charge to ionic radius) or the most electronegative are first adsorbed, and if there are still available sites, then the lower charge density or lower electronegative ion is adsorbed in sequence. This would fit with the known electronegativities for the studied metal ions, i.e. $\mathrm{Pb}(2.33)>\mathrm{Zn}(1.65)$. Also, when a hydrated ion is subjected to electrostatic interactions, the rate of the solvent exchange between the hydration shells of an ion and the bulk of the water is determined by the ligand field stabilisation and the electric field of the ion. The electric field determines the rate of the solvent exchange in a way that the larger the field strength, the slower the exchange (Marcus 1988; Burgess 1999). Knowing that the charge density around $\mathrm{Zn}^{2+}$ is greater than that around $\mathrm{Pb}^{2+}$, the exchange of solvent $\left(\mathrm{H}_{2} \mathrm{O}\right)$ around $\mathrm{Pb}$ will be faster than that for $\mathrm{Zn}$ and this is another potential explanatory factor for the adsorption of the $\mathrm{Pb}$ being slightly more than that for $\mathrm{Zn}$.

\section{Desorption of $\mathrm{Pb}$ and $\mathrm{Zn}$}

The very low desorption rates, and thus strong retention of $\mathrm{Pb}$ and $\mathrm{Zn}$, observed in this study suggest that not only outersphere (electrostatic bonding) complexes form between solute metals and WTRs but also inner-sphere complexes (ionic or covalent bonding directly with surface functional groups), the assertion of which is certainly further supported by the $\mathrm{H}$-shaped isotherms for $\mathrm{Pb}$ (Sparks 2003). Quantitatively important inner-sphere complexes have been noted for adsorption of $\mathrm{Pb}$ to $\mathrm{Al}, \mathrm{Fe}$ and $\mathrm{Mn}$ (hydr)oxides as well as for $\mathrm{Zn}$ sorption to $\mathrm{Al}, \mathrm{Fe}$ and $\mathrm{Mn}$ (hydr)oxides in the literature (e.g. Trainor et al. 2000; Matocha et al. 2001), further supporting this idea. It is also known that in the presence of a ligand such as $\mathrm{SO}_{4}{ }^{2-}$ or $\mathrm{CO}_{3}{ }^{2-}$ a ternary complex can occur in which the ligand is between the surface functional group and the metal, acting as a bridge. When this occurs, the solubilities of metals and ligand drop below those expected from either adsorption or precipitation alone (Roberts et al. 2005); thus, the ligands present in the WTRs could also play a role in enhancing the sorption and retention. Adsorption of $\mathrm{Pb}$ onto goethite and of $\mathrm{Zn}$ onto alumina powder was notably enhanced by the presence of ligand bridges through formation of inner-sphere bidentate binding via ternary complexes (Ostergren et al. 2000; Trainor et al. 2000); thus, it is also a real possibility within the suite of mechanisms by which WTRs sorb and retain metals. Application of scanning electron microscopy (SEM), X-ray diffraction (XRD) and Fourier-transform infrared spectroscopy (FTIR) techniques to WTRs recovered from batch sorption experiments such as those conducted in the present study may be able to provide more definitive information on the bonding mechanisms 
involved, as such steps have been successfully implemented elsewhere in studies of other sorbing materials (Wang et al. 2021; Zhu et al. 2021); future research with WTRs should incorporate this.

\section{Conclusion}

This investigation has shown that the two WTRs tested, Albased and Fe-based, had high adsorption capacity for $\mathrm{Pb}$ and $\mathrm{Zn}$ both separately and in combination, with $>93 \%$ of each of the metals in solution removed at every concentration tested. Through examination of fits to the data of multiple isotherms, it was demonstrated that multiple sorption mechanisms are likely involved in the sorption of metals by WTRs. Moreover, the WTRs retained the vast majority of the adsorbed metals even through a vigorous desorption process, confirming their potential for environmental applications in which immobilisation or removal of metals is desirable.

Acknowledgement The authors gratefully acknowledge funding from the Ministry of Higher Education and Scientific Research, Iraq (B859).

Conflict of interest The authors declare that they have no known competing interests or conflicts of interest. The authors have permission from Keele University to publish this work.

Open Access This article is licensed under a Creative Commons Attribution 4.0 International License, which permits use, sharing, adaptation, distribution and reproduction in any medium or format, as long as you give appropriate credit to the original author(s) and the source, provide a link to the Creative Commons licence, and indicate if changes were made. The images or other third party material in this article are included in the article's Creative Commons licence, unless indicated otherwise in a credit line to the material. If material is not included in the article's Creative Commons licence and your intended use is not permitted by statutory regulation or exceeds the permitted use, you will need to obtain permission directly from the copyright holder. To view a copy of this licence, visit http://creativecommons.org/licenses/by/4.0/.

\section{References}

Babatunde AO, Zhao YQ (2007) Constructive approaches toward water treatment works sludge management: an international review of beneficial reuses. Crit Rev Environ Sci Technol 37:129-164

Basibuyuk M, Kalat D (2004) The use of waterworks sludge for the treatment of vegetable oil refinery industry wastewater. Environ Technol 25:373-380

Bonilla-Petriciolet A, Mendoza-Castillo DI, Reynel-Avila HE (2017) Adsorption processes for water treatment and purification. Springer, Berlin

Burgess J (1999) Ions in solution: basic principles of chemical interactions. Elsevier, Amsterdam

Chen Z, Xing B, Mcgill W (1999) A unified sorption variable for environmental applications of the Freundlich equation. J Environ Qual 28:1422-1428
Chiang YW, Ghyselbrecht K, Santos RM, Martens JA, Swennen R, Cappuyns V, Meesschaert B (2012) Adsorption of multi-heavy metals onto water treatment residuals: Sorption capacities and applications. Chem Eng J 200-202:405-415

Cimino G, Passerini A, Toscano G (2000) Removal of toxic cations and $\mathrm{Cr}(\mathrm{Vi})$ from aqueous solution by hazelnut shell. Water Res 34:2955-2962

Coles CA, Yong RN (2006) Use of equilibrium and initial metal concentrations in determining Freundlich isotherms for soils and sediments. Eng Geol 85:19-25

Dada AO, Olalekan AP, Olatunya AM, Dada O (2012) Langmuir, Freundlich, Temkin and Dubinin-Radushkevich isotherms studies of equilibrium sorption of $\mathrm{Zn}^{2+}$ unto phosphoric acid modified rice husk. IOSR J Appl Chem 3:38-45

Dash M, Dwari RK, Biswal SK, Reddy PSR, Chattopadhyay P, Mishra BK (2011) Studies on the effect of flocculant adsorption on the dewatering of iron ore tailings. Chem Eng J 173:318-325

Howe KJ, Crittenden JC, Hand DW, Trussell RR, Tchobanoglous G (2012) Principles of water treatment. Wiley, Hoboken

Howells AP, Lewis SJ, Beard DB, Oliver IW (2018) Water treatment residuals as soil amendments: examining element extractability, soil porewater concentrations and effects on earthworm behaviour and survival. Ecotoxicol Environ Saf 162:334-340

Ippolito JA, Barbarick KA, Elliott HA (2011) Drinking water treatment residuals: a review of recent uses. J Environ Qual 40:1-12

Keeley J, Jarvis P, Judd SJ (2014) Coagulant recovery from water treatment residuals: a review of applicable technologies. Crit Rev Environ Sci Technol 44:2675-2719

Kim Y, Kim C, Choi I, Rengaraj S, Yi J (2004) Arsenic removal using mesoporous alumina prepared via a templating method. Environ Sci Technol 38:924-931

Liu X, Pang H, Liu X, Li Q, Zhang N, Mao L, Qiu M, Hu B, Yang H, Wang X (2021) Orderly porous covalent organic frameworksbased materials: superior adsorbents for pollutants removal from aqueous solutions. Innovation 2:100076

Lowell S, Shields JE, Thomas MA, Thommes M (2012) Characterization of porous solids and powders: surface area, pore size and density. Springer, Berlin

Makris KC, El-Shall H, Harris WG, O'connor GA, Obreza TA (2004) Intraparticle phosphorus diffusion in a drinking water treatment residual at room temperature. J Colloid Interface Sci 277:417-423

Marcus Y (1988) Ionic radii in aqueous solutions. Chem Rev 88:1475-1498

Matocha CJ, Elzinga EJ, Sparks DL (2001) Reactivity of Pb (II) at the Mn (III, IV)(oxyhydr) oxide-water interface. Environ Sci Technol 35:2967-2972

Mcbride MB (1989) Reactions controlling heavy metal solubility in soils. Adv Soil Sci 10:1-47

OECD (2000) Test No. 106: Adsorption-Desorption Using a Batch Equilibrium Method.

Ostergren JD, Brown GE Jr, Parks GA, Persson P (2000) Inorganic ligand effects on $\mathrm{Pb}$ (II) sorption to goethite $(\alpha-\mathrm{FeOOH})$ : II. Sulfate. J Colloid Interface Sci 225:483-493

Pehlivan E, Cetin S, Yanik BH (2006) Equilibrium studies for the sorption of zinc and copper from aqueous solutions using sugar beet pulp and fly ash. J Hazard Mater 135:193-199

Prakash P, Sengupta AK (2003) Selective coagulant recovery from water treatment plant residuals using donnan membrane process. Environ Sci Technol 37:4468-4474

Roberts D, Nachtegaal M, Sparks D L (2005) Speciation of metals in soils. In: Chemical Processes in Soils. Madison, WI. Soil Science Society of America

Silvetti M, Castaldi P, Garau G, Demurtas D, Deiana S (2015) Sorption of cadmium (II) and zinc (II) from aqueous solution by water 
treatment residuals at different $\mathrm{pH}$ values. Water Air Soil Pollut 226:313

Sparks DL (2003) Environmental Soil Chemistry, 2nd edn. Academic Press, Cambridge

Trainor TP, Brown GE Jr, Parks GA (2000) Adsorption and precipitation of aqueous $\mathrm{Zn}$ (II) on alumina powders. J Colloid Interface Sci 231:359-372

Turner T, Wheeler R, Stone A, Oliver I (2019) Potential alternative reuse pathways for water treatment residuals: remaining barriers and questions-a review. Water Air Soil Pollut 230:227

Üçer A, Uyanik A, Aygun SF (2006) Adsorption of Cu(II), Cd(II), $\mathrm{Zn}(\mathrm{II}), \mathrm{Mn}(\mathrm{II})$ and $\mathrm{Fe}(\mathrm{III})$ ions by tannic acid immobilised activated carbon. Sep Purif Technol 47:113-118

Vazquez G, Antorrena G, Gonzalez J, Doval MD (1994) Adsorption of heavy metal ions by chemically modified Pinus pinaster bark. Biores Technol 48:251-255
Wang Z, Jia Y, Song W, Li X, Xu K, Wang Z (2021) Optimization of boron adsorption from desalinated seawater onto UiO-66-NH2/ GO composite adsorbent using response surface methodology. J Clean Prod 300:126974

Yildirim EH (2006) Surface chemistry of solid and liquid interfaces. J Adhes 83:507-508

Zhou Y-F, Haynes RJ (2011) Removal of Pb (II), Cr (III) and Cr (VI) from aqueous solutions using alum-derived water treatment sludge. Water Air Soil Pollut 215:631-643

Zhu Y, He X, Xu J, Fu Z, Wu S, Ni J, Hu B (2021) Insight into efficient removal of $\mathrm{Cr}(\mathrm{VI})$ by magnetite immobilized with Lysinibacillus sp JLT12: mechanism and performance. Chemosphere 262:127901 